\title{
Justification, Attachments and Regret
}

\author{
Josep E. Corbí | University of Valencia \\ European Journal of Philosophy, v. 25, No. 4, pp. 1718-1738
}

Abstract: In The View From Here, Jay Wallace emphasises that an agent's capacity to regret a past decision is conditioned by the attachments that she may have developed as a result. Those attachments shape the point of view from which she retrospectively deliberates. Wallace stresses, however, that not every normative aspect of her decision is affected by this change in perspective, since her decision will remain as unjustified as it was in the past. I will argue, however, that this approach to justification is inconsistent with the normative import that Wallace ascribes to the actual dynamics of our attachments in his defence of the rationale of regret. If I am right, Wallace's approach is caught in the following dilemma: either he renounces a non-perspectival approach to justification or he revises his view about the normative import of the actual dynamics of our attachments.

In The View From Here: On Affirmation, Attachment and the Limits of Regret (2013), Jay Wallace emphasises that an agent's capacity to regret a past action or decision is conditioned by the attachments she may have developed as a result of this past action or decision. Wallace examines in some detail the case a girl who decides to conceive a child at the age of sixteen. A decade later, the young mother is so fond of her daughter that she is unable to regret her decision. Her attachment to her daughter shapes the viewpoint from which she retrospectively deliberates about her decision. Wallace refers to this later perspective as 'the view from here'. Not every normative aspect in her decision is affected by this change in perspective, though. The young mother's decision remains, according to Wallace, as unjustified when reflecting in retrospection as it was in the past. He applies a similar line of reasoning to Gauguin's decision to leave his family in the lurch and move to Martinique to develop his career as a painter. He thus departs from Bernard Williams' analysis according to which Gauguin's success as a painter provides the latter with some ground to justify his decision. Wallace objects that the fact that a 
successful Gauguin may be unable to regret his past decision does not imply that it was retrospectively justified; in fact, Wallace argues that a non-perspectival notion of justification (i.e., a notion that is not affected by the view from here) is indispensable to make sense of the claims that his wife and children can legitimately level against him. A consequence of this line of reasoning is that, even though a successful Gauguin may unable to regret his decision, he is not thereby in a position to affirm his life without ambivalence. And this is, according to Wallace, Gauguin's predicament. ${ }^{1}$

I will argue, however, that Wallace's non-perspectival approach to justification is inconsistent with the normative import that he ascribes to the actual dynamics of our attachments in his defence of the rationale of regret. In my view, this normative import imposes some perspectival constraints on practical deliberation that are ultimately relevant to the conditions under which a certain decision or action may be justified. If I am right, Wallace's approach is caught in the following dilemma: either he renounces a non-perspectival account of justification or he revises the normative import granted to our attachments in his defence of the rationale of regret. There is reason, however, to skip the latter, for, otherwise, we would have to engage in a vast reconstruction of our experiences, as Williams (1981) puts it, that conflicts with the demands that reflective equilibrium imposes upon this kind of philosophical reflection (Goodman 1983; Rawls 1999, 2001).

The paper is structured like this. In section 1, I will present Wallace's defence of the rationale of regret in terms of its role in the actual dynamics of our attachments; in section 2, I will sketch Williams' perspectival view about justification, where situation, audience, and reason perspectivism will be distinguished; and then I will present Wallace's objections to situation and audience perspectivism. In sections 3, I will elaborate on the idea that the wronged person is the bearer of a claim and examine the kind of deliberation that may lead her to withdraw or to keep her claim. This will prepare the ground for section 4, where I will examine Primo Levi's experience of shame in order to highlight a number of asymmetries between what I regard as the three poles of harm, namely: the executioner, the victim and a third party. Such asymmetries imply, in my view, both situation and audience perspectivism. I will thus conclude that Wallace cannot coherently preserve two fundamental claims in his book, namely: a non-perspectival approach to justification and a vindication of the rational regret in terms of the normative authority of the actual dynamics of our attachments. 


\section{The Rationale of Regret}

Regret looks back onto a past event or action with pain: one wishes that things had been otherwise. Some people worry about the rationale of this attitude given that nothing can be done to change the past:

The challenge was to elucidate the point or rationale of feelings of this kind, given their unpleasant phenomenology and the fact that at the time they are experienced, it is no longer possible to do anything about the events that gave rise to them. (Wallace 2013: 30)

This challenge presupposes a certain conception of practical rationality: pain or sorrow only makes sense if it motivates the agent to act in ways that contribute to repairing the damage caused. In other words, this conception assumes that the unpleasant aspect of an emotion must be balanced with some beneficial effect for this emotion to have any rationale at all. In this respect, it could certainly be replied that regret often has some beneficial sequels insofar as it may act as a deterrent or as an incentive in the future. Wallace feels dissatisfied, however, with a merely instrumental defence of regret, for it fails to apprehend its deep significance in our lives. Regret is, instead, vindicated as a constitutive aspect of our attachments and, in the end, of our capacity to value.

Valuing must be distinguished, however, from the mere endorsement of an evaluative judgment, since the former, unlike the latter, requires some sort of emotional engagement with an active interest in the object under consideration (Wallace 2013: 23). And it is precisely an aspect of our valuing a situation $S$ that it renders us vulnerable to how $S$ fares or evolves. If a father loves his daughter, then sorrow or pain at her misfortunes comes as an aspect of his valuing her and not just as a means to encourage him to protect her more efficiently in the future. In other words, we can say that his regret is a constitutive aspect of his attachment to his daughter:

It is the investment of things with personal interest and importance that renders one susceptible of both of these forms of affect; the positive and the negative tendencies are thus two sides of the same coin, constitutively connected to each other as different aspects of a single underlying syndrome or stance. So, it isn't a real option for us to attempt to retain the positive dispositions that the syndrome involves while jettisoning the vulnerability to retrospective sadness. (Wallace 2013: 25-6) 
There is no room, however, for the ulterior question as to what the rationale of having attachments might be, ${ }^{2}$ since, according to Wallace, our attachments are '.. the main source of meaning, and a constitutive part of human flourishing or well-being.' (Wallace 2013: 31) One might certainly object to the appropriateness of being attached to some kinds of objects, ${ }^{3}$ but Wallace denies, in a rather Strawsonian spirit (Strawson 2008: 1-28), that the importance of our valuings or attachments as a whole could intelligibly be challenged. ${ }^{4}$ Notice, for this purpose, the two phrases in italics in the previous quotation. The first one emphasises the existence of a constitutive connection between the positive and the negative aspects of our attachments, whereas the second points to what looks like a mere psychological impossibility ('it's not an option for us'). ${ }^{5} \mathrm{We}$ can forsake this apparent inconsistency, though, by assuming that the options actually open to us contribute to fixing the constitutive features of our attachments, and vice versa. All this suggests that Wallace defends the view that the appropriateness of an emotional response must be assessed by reference to the actual dynamics of our valuings and, in the end, of our attachments.

This is not to deny, however, that the assessment of our actions and attitudes '.. is fixed by objective standards of some kind.' (Wallace 2013: 9) Moreover, Wallace equates 'objective' to 'independent of us' as he claims:

I have taken it for granted, throughout my discussion, that our actions and attitudes are subject to normative assessment, and that the terms of such assessment are independent of us. (Wallace 2013: 254)

There is no indication in his book, however, as to how 'objective' and 'independent of us' must be construed, even though his elucidation of the rationale of regret suggests that a proper account of these notions must allow for the standards of objective assessment to be constrained by the way we actually respond to one or another situation. For the sake of argument, we can then assume that there are such standards and, therefore, that 'objective' can be construed in a way consistent with the normative significance of our actual feelings and attitudes vindicated in the passages above. ${ }^{6}$

Objective standards thus construed include, according to Wallace, agent-relative reasons like those that an agent's attachments provide: 
There are reasons for action and for emotion, and these determine facts of the matter about what we should do and think and feel. Among other things, our attachments give us agentrelative reasons, looking forward, for various actions and attitudes that we wouldn't have reason to adopt in their absence. (Wallace 2013: 9) ${ }^{7}$

The appeal to 'facts of the matter', which comes a few lines after Wallace's appeal to objective standards, invite the thought that some reasons are agent-relative but only insofar as they apply exclusively to those agents who are in a particular situation or, more specifically, to those with a specific character. But this is a fact that a third party is also in a position to determine and, therefore, no deliberative privilege is preserved for the agent herself. In section 3, I intend to argue that the normative import that Wallace concedes to our attachments in his defence of the rationale of regret, implies a stronger notion of agent-relative reasons, namely, a notion that opens up a deliberative gap between the first-person and the third-person perspectives, so that there are some crucial normative issues about which a third party must suspend judgment and leave them for the agent herself to articulate. This stronger notion of agent-relative reason will finally favour a perspectival approach to justification. But let me first present Williams' analysis of Gauguin's case and Wallace's reply to it. For this purpose, three kinds of perspectivism about justification will be distinguished: situation, audience and reason perspectivism.

\section{Wallace's Case Against Perspectivism}

In 'Moral Luck', Williams vindicates the retrospective character of justification. He argues that Gauguin's success as a painter provides him with a basis to justify his decision to move to Martinique and, thereby, to leave his family in the lurch:

If he [Gauguin] fails... then he did the wrong thing.... in the sense that having done the wrong thing in those circumstances he has no basis for the thought that he was justified in acting as he did. If he succeeds, he does have a basis for that thought. (Williams 1981: 23)

An important aspect in William's proposal is that Gauguin's capacity to justify himself is not only conditional upon his success as a painter, but also relative to the particular audience he addresses on each particular occasion. Gauguin's remarkable contribution to the history of European painting may justify his decision to himself but hardly so to his wife and children. His 
success has not earned him the right to dismiss their reproach, although they may eventually withdraw their claim in view of his success:

The idea that there has been a moral cost itself implies that something bad has been done, and, very often, that someone has been wronged, and if the people who have been wronged do not accept the justification, then no-one can demand that they should. It is for them to decide how far they are prepared to adopt the perspective within which the justification counts. (Williams 1981: 37; see 23)

Gauguin's success may, instead, justify his decision to a third party. The gratitude that we feel for Gauguin's paintings may express the conviction that his decision was after all justified. Even though we do acknowledge the moral cost of the decision, we allow for non-moral reasons to prevail. ${ }^{8}$ The kind of justification achieved in those cases does not go as far, however, as to cancel the right of those who have been wronged to complain.

We can thus conclude that Williams's notion of justification is perspectival not only because (a) the view from here opposes the view from there (i.e., the view at the time of the decision) and (b) the justificatory force of a narrative is relative to the particular audience it is addressed to, but also because (c) the moral perspective needn't always prevail and sometimes a wider perspective will emerge as the right perspective from which to examine one's justificatory concerns. In light of these remarks, we can distinguish three ways in which the notion of justification could be perspectival, namely: the proper answer to the question as to whether a certain action or decision is justified could be relative to the particular situation from which the agent raises it, the audience to which it is addressed or the kinds of reasons that are regarded as relevant. We can correspondingly differentiate between situation, audience and reason perspectivism. Wallace's case against a perspectival account of justification leaves aside reason perspectivism as a live question and focuses on situation and audience perspectivism. His point is, indeed, that justification is not perspectival in either way. Let me then consider Wallace's stance on reason perspectivism first.

Wallace regards reason perspectivism as a live option and, therefore, suspends judgment as to whether moral reasons should always prevail. ${ }^{9}$ He does not see this indetermination as a problem for his discussion of Gauguin's case because, in his view, the argument in 'Moral Luck' is not at all concerned with this kind of perspectivism: 
Williams himself has argued that our ground projects place limits on what we can rationally be required to do, and that the normative force of moral considerations is undermined when they conflict fundamentally with the things that gives us reason to go on in life in the first place. But that is not the argument that he makes in 'Moral Luck'. The claim here is not about the rational force of moral vs. other considerations in the deliberative situation that confronts Gauguin in Paris but about the retroactive significance of his later standpoint of assessment, after he has become a massively successful artist. (Wallace 2013: 166)

I agree that reason perspectivism is not Williams' fundamental concern in 'Moral Luck', but it is easy to see that it plays a crucial role in the main line of argument. Williams stresses that Gauguin's decision has a moral cost and regards this fact as the fundamental reason why his wife and children have a claim to make against him. Still, he argues that Gauguin's decision could be justified retrospectively and, therefore, he must assume that there is a point of view from which moral costs can be overridden by some other benefits. So, it seems that the main argument in 'Moral Luck' presupposes reason perspectivism. ${ }^{10}$ Be that as it may, given that Wallace regards the primacy of moral reasons as a live question, it is at least clear that he cannot coherently rely on the primacy of moral reasons to develop his challenge to situation and audience perspectivism. And this constraint will be crucial at a certain stage in my case against Wallace's defence of a non-perspectival approach to justification.

Regarding audience perspectivism, Wallace explores mainly the young mother's case. He claims that, given that her daughter has evolved into a happy and self-sufficient person, the young mother has little reason to regret her decision as a teenager. Moreover, if her daughter finally celebrates her own existence and withdraws any claims she could have levelled against her mother, there will be nothing left for her mother to regret:

The general principle at work in this example, it appears, is that the normative force of claims as grounds for retrospective preference is undermined if the bearers of those claims themselves now actually prefer, on balance, that their claims should not have been acknowledged. Their de facto present preferences regarding the past action, based in their own ongoing attachments, trump their moral claims as potential normative bases for regret, at least so long as those preferences are based on a truthful understanding of their objects. (Wallace 2013: 178-9) 
And, yet, Wallace insists that the daughter's celebration leaves unaltered the fact that the young mother's decision was unjustified. In fact, it is precisely the fact that the mother's decision was unjustified that renders it intelligible that the daughter is the bearer of a claim that she may eventually decide to withdraw. She was not actually wronged by her mother's decision, but the fact that she could not have been raised in an appropriate environment as a result of an unjustified decision, places her in a position to keep or withdraw her claim.

Wallace applies this line of reasoning to Gauguin's decision as well. Unlike the daughter, Gauguin's wife and children were actually wronged by his decision and this fact makes of them the bearers of a claim and, therefore, places them in a privileged position as to whether to withdraw or keep their claim. This privileged position is the product of them having been wronged by an unjustified decision and, therefore, the actual withdrawal of their claim can hardly be construed as expressing the view that the decision was after all justified:

It is a salient feature of both of these examples that the objections to the agent's earlier actions are in part of a moral nature, grounded in the claims of other parties whose lives are affected by what the agents have done. A retrospective failure to acknowledge the strength of those objections would therefore involve an attitude of continuing disregard for those claims on the part of the mother... But the retrospective concern for justification has a point even in situations in which specifically moral objections are not at issue. (Wallace 2013: 171; see 175)

The argument against audience perspectivism reveals, according to Wallace, that 'there is simply no good reason to suppose that questions of rational justification and questions of rational regret will track each other systematically in the way that Williams relies upon.' (Wallace 2013: 165; see 133) Moreover, it seems that we can only account for the complexity of the situation if we assume that the decision was unjustified, even though the young mother or Gauguin may be in a position to legitimately affirm their decision. As a result, we also have serious reason to reject situation perspectivism and thus Wallace can conclude that 'whether Gauguin's decision was justified, or rationally justified, is a question of what he had reason to do at the time when the decision was made.' (Wallace 2013: 165) ${ }^{11}$ In the next section, I will elaborate on what is involved in the claim that Gauguin's wife is the bearer of a claim and the sort of deliberation that may legitimately induce her to keep or withdraw her claim. This will help us to show, in section 4, why situation and audience perspectivism may lie at the heart of 
Primo Levi's shame as a survivor of Auschwitz and the way he responds to it. Some implications will finally be drawn for Gauguin's and the young mother's cases.

\section{The Bearer of a Claim and the Notion of Practical Necessity}

Wallace seems to tightly connect the fact that Gauguin's decision was unjustified with the fact that his wife and his children were wronged. He argues that we can only make sense of his wife's claim on the assumption that Gauguin's decision was unjustified. It is unclear, however, whether a lack of justification is a necessary condition for a person to be wronged. If we keep justification within the moral domain, there are moral dilemmas where one or another party must be wronged and this hardly implies that the agent's decision to undertake one course of action rather than another is unjustified. The same applies to non-moral reasons insofar as they are allowed to prevail over moral reasons in some particular circumstances. Even when nonmoral reasons prevail, there will still be a moral cost but this fact by itself will not render the decision unjustified. ${ }^{12}$ Wallace's argument against audience perspectivism requires then a denial of reason perspectivism, for only on this assumption could one grant that Gauguin's decision was unjustified because of its moral cost and regardless of his inability to regret. Wallace wanted to remain neutral concerning reason perspectivism, but, as we have seen, such neutrality undermines his case against audience perspectivism. Let me now elaborate on a positive argument for audience perspectivism and, for this purpose, a particular aspect of the dynamics of our attachments will be examined, namely: the wronged person's entitlement to withdraw her claim.

Wallace emphasises the privileged status of the wronged person. He emphasises that she is the bearer of a claim because only she is entitled to withdraw it. If the view that the wronged person is the bearer of a claim is to have any specific content, any rational constraints that a third-party could apply fall short of determining what the wronged person must do, that is, whether to withdraw or to keep her claim, for otherwise, what would remain of her alleged privilege? Hence, the privileged status conferred to the wronged person implies the recognition of a first-person kind of deliberation in light of which the practical question 'How should I respond to this situation?' has to be answered. Any rational constraints that could be applied from a third-person perspective will contribute to delineating the space of legitimate actions, but they could hardly determine the particular course of action that the wronged person must undertake. Let us now enquire as to how the wronged person must deliberate within this strictly first-person perspective. ${ }^{13}$ 
Some may be inclined to render any decision or answer to the practical question on the side of the wronged person as just a matter of choice, where reason has nothing to say. This is the only option available if we stick to a non-perspectival notion of rationality: all there is to rationality must be determined from a third-person perspective, that is, from an impartial point of view. The point is whether the wronged person experiences her situation as just requiring a choice on her side or else as a confrontation with some sort of necessity, namely, a kind of necessity that is rational and, yet, strictly first-personal. I propose to take advantage of Williams' notion of acknowledgment to explore the idea of a first-person kind of deliberation that does not reduce to the idea of choice. Williams introduces this notion to account for the way an agent relates to her religious or national identity:

A relevant notion here is acknowledgement. Someone may come to acknowledge a certain affiliation as an identity, and this is neither a mere discovery nor, certainly, a mere decision. It is as though he were forced to recognise the authority of this identity as giving a structure and a focus to his life and his outlook. There were circumstances in which what was earlier a mere recognition of a fact may come to compel acknowledgement, as when many assimilationist Jews in the 1930s came to acknowledge a Jewish and perhaps a Zionist identity under the thought that there was no way in which without evasion they could go on as though it made no difference that they were Jewish people. (Williams 2002: 203; my emphasis)

It is a well-known fact that, before the Nazi ascent, many German Jews regarded their Jewishness as a trivial fact about themselves. The subsequent change in the social and political circumstances forced them to approach this fact quite differently, namely, as crucial to their lives and, therefore, to their identity. Their acknowledgement of their Jewish identity did not then reduce to the discovery of a fact, since it included the idea that the fact discovered was crucially important to their lives. On the other hand, the idea of a decision does not suffice either because any such decision may fail to adequately permeate the agent's psychological dispositions (Moran 2001: 81). This is why Williams places acknowledgment between a mere discovery and a mere decision.

This notion can easily be applied to other projects an agent may be committed to, like Gauguin's ambition to make a contribution to the history of European painting or the young mother's decision to conceive a baby. The significance of any such project in the agent's life is determined by the cost of her incapacity to develop it or to meet its demands. This incapacity I am alluding to does not derive from some external factors but has to do with a resistance on the 
side of the agent's psychological dispositions and, complementarily, the risk of indulging in wishful thinking and fantasy. The young mother decided to have a baby. She was lucky enough to raise her daughter quite successfully, but she might have failed to enjoy rearing her daughter, no matter how hard she might have tried; she may even secretly blame her daughter for her discomfort and frustration. So, it seems that an agent's ability to identify herself with a certain project cannot be reduced to a mere decision and includes an element of discovery. To have a more unified account of what this attitude may consist of, we can shift to another expression in the previous quotation, namely: 'being forced to recognise the authority of this identity'.

This notion points to a sort of imposition that does not simply come from inside, like an act of will or a psychological disposition, but also from outside, that is, as something the agent is confronted with. ${ }^{14}$ And, yet, this external element is invested with authority and, therefore, it is not perceived as a mere fact to be discovered. This is the experience of practical necessity that Williams explores in a number of contexts:

The experience is like being confronted with something, a law that is part of the world in which one lives... It is the conclusion of practical necessity, no more and no less, and it seems to come 'from outside' in the way that conclusions of practical necessity always seem to come from outside -from deeply inside. Since ethical considerations are in question, the agent's conclusions will not usually be solitary or unsupported, because they are part of an ethical life that is to an important degree shared with others. (Williams 2002: 190-1) ${ }^{15}$

The notion of practical necessity is relevant not only to understand how an agent relates to her religious or national identity, but also to apprehend the kind of imposition that is involved when she accepts the conclusion of a sound argument or adapts her perceptual beliefs to what she sees in her surroundings. This sensitivity to a good argument or to her surroundings conveys the recognition of the authority of some external facts to alter her beliefs (Stroud 2011). Some may call into question the intelligibility of this notion of practical necessity insofar as it relies on the idea that some external facts do have a normative import independently of how the agent responds to it. This raises the issue about moral realism that was briefly addressed in the previous section. There, I concluded that Wallace's line of argument must elaborate on a notion of objective value that is consistent with his claim that the actual dynamics of our attachments constitutes the bedrock on which to determine whether a given attitude is rational or irrational. This kind of objective value is, however, all the notion of practical 
necessity needs to rely upon and, therefore, Wallace could not reasonably challenge this notion on such grounds.

In the coming section, I will firstly examine Primo Levi's elucidation of his experience of shame as a survivor in light of Williams' notions of acknowledgement and practical necessity. In this case, we are concerned with a situation with a high degree of uncertainty as to what an agent is forced to do and where some asymmetries between the first- and the third-person perspectives emerge. Secondly, I will derive some implications for Gauguin's case and, finally, conclude that both situation and audience perspectivism must be assumed to make sense of Levi's and Gauguin's cases.

\section{Primo Levi's Shame and the Three Poles of Harm}

At some point in The Drowned and the Saved (1986), Levi reflects upon his experience of shame long after his survival from Auschwitz. Shame was for him an unexpected emotion. In the extermination camp, he imagined his unlikely liberation as a cheerful and light-hearted experience. His liberation came, however, with an obscure anguish whose source he was for some time unable to ascertain. After a long process of reflection, he identified it as a sense of shame or guilt that had to do with his condition as a survivor from Auschwitz. It was not easy for Levi to determine what exactly he felt ashamed of, though. A number of omissions, actions and circumstances are finally mentioned as the source of his shame. Firstly, the fact that he had accepted to be humiliated and diminished (Levi 1986: 56-7); secondly, some minor failures in terms of solidarity that retrospectively acquired an enormous significance (Levi 1986: 58-9); thirdly, his cooperation, however small, with the Nazi machinery (Levi 1986: ch. 2); fourthly, the image of the drowned and the thought that he might be alive at their expense (Levi 1986: 62); and, finally, the conviction that, regarding the horror of extermination camps, 'no man is an island' and other people's guilt is one's own too (Levi 1986: 65).

Still, Levi could not regard his shame or guilt as rational. He is convinced that prisoners in Auschwitz (himself included) were typically deprived of the required margin of manoeuvre to be held responsible for their acts. In a few, exceptional cases he deems blame justified but, in general, he strongly objects to the idea that survivors could be blamed for what they did or failed to do in the extermination camp. Not even the members of the Sondernkommandos in front of whose deeds Levi himself suspends judgement. Thus, Levi concludes at some point: 
Therefore, on a rational plane, there should not have been much to be ashamed of, but shame persisted nevertheless, especially before the few, bright examples of those who had the strength and possibility to resist. (Levi 1986: 58; see 54)

Nevertheless, the question as to whether his shame was justified keeps coming back to him and quite often he views it as unresolved:

Is this belated shame justified or not? I was not able to decide then and I am not able to decide even now, but shame was there and is there, concrete, heavy, perennial. (Levi 1986: 65)

Levi seems then unable to regard his shame as rational but also to dismiss it as merely irrational. In fact, if we focus not so much on his explicit declarations about the rationality of his shame but on the sort of project he engaged in after his liberation, we can hardly escape the conviction that he placed his shame at the heart of his life. He devoted a significant amount of time and energy to writing about his experience in Auschwitz and as a survivor, and he presents this writing as guided by 'a strong and durable impulse' that is somewhat connected to the drowned:

We who were favoured by fate tried, with more or less wisdom, to recount not only our fate, but also that of others, the submerged; but this was a discourse on 'behalf of third parties', the story of things seen from close by, not experience personally.... We speak in their stead, by proxy.

I could not say whether we did so or do so because of a kind of moral obligation towards those who were silenced, or rather in order to free ourselves of their memory; certainly we do it because of a strong and durable impulse. (Levi 1986: 64)

How is Levi's 'strong and durable impulse' to be construed, though? He emphatically rejects an interpretation of it in psychoanalytic terms, that is, as calling for some sort of cure. This approach is dismissed partly on the grounds that psychoanalysts, despite their expertise, have an external, third-person perspective on the relevant facts (Levi 1986: 64-5). A deliberative distance between the survivors and a third party is thereby emphasised. Moreover, Levi confesses in the previous quotation his own limitations to voice the claims of the drowned, for, regarding the latter, the survivors themselves must be conceived of as a third-party. In these circumstances, we can easily understand why Levi, and other survivors, reacted bitterly against 
those who, despite their lack of experience in Auschwitz, felt entitled to judge the survivors both in the camp and in the aftermath:

Changing moral codes is always costly: all heretics, apostates, and dissidents know this. We cannot judge our behaviour or that of others, driven at that time by the code of that time, on the basis of today's code; but the anger that pervades us when one of the 'others' feels entitled to consider us 'apostates' or, more precisely, reconverted, seems right to me. (Levi 1986: 61)

I see all these asymmetries between the first- and the third-persons perspectives as connected to Levi's inability to concede the rationality of his shame and, therefore, to acknowledge the normative import of the 'strong and durable impulse' that led his life as a survivor. In particular, I will argue that the two following assumptions stand in the way of Levi's recognition:

The Control Assumption: My shame of having done (or failed to do) X is rational only if I had a reasonable margin of manoeuvre to act otherwise.

The Third-Party Assumption: If my shame of having done (or failed to do) $\mathrm{X}$ is rational, then a third party is entitled to blame me. ${ }^{16}$

Levi does not explicitly call the Control Assumption into question; in fact, some of his comments seem to corroborate it; for instance, when he assumes that the lack of a reasonable margin of manoeuvre undercuts the legitimacy of any accusation. And, yet, as he dissects the nature of his shame, he emphasises that a person can rightly feel guilty for things that someone else had done:

It was not possible for us, nor did we want, to become islands; the just among us, neither more nor less numerous than in any other human group, felt remorse, shame and pain for the misdeeds of others and not they had committed, and in which they felt involved, because they sensed that what had happened around them in their presence, and in them, was irrevocable. (Levi 1986: 66)

Some room seems to be made for a concept of responsibility that goes beyond the Control Assumption. But Levi could not have safely dropped this assumption while preserving the 
Third-Party Assumption because, in such a case, a third-party would be entitled to accuse him and, therefore, his bitter reaction at any such accusation should be dismissed as unjustified.

Suppose, on the contrary, that Third-Party Assumption is dropped, then an asymmetry between the first- and the third-person perspectives would be granted: an agent could legitimately regard his shame as rational even though no one else could rightly blame him. This asymmetry leaves Levi in a position to renounce the Control Assumption without allowing a third-party to accuse him. ${ }^{17}$ Once the Control and the Third-Party assumptions are dropped, we must concede that some attitudes can be justified but only from a first-person point of view, that is, in virtue of some practical necessity that the agent might acknowledge and about which a third party is bound to suspend judgment. What are, however, the implications of this asymmetry for a perspectival view about justification?

Some people might state that there are none given that, unlike what happens in Gauguin's and the young mother's cases, Levi's reflection focuses on a present emotion rather than on a past action or decision. It could be replied, however, that shame is an emotion whose object lies at some point in the past and is typically concerned with what the agent did or failed to do at the time. Levi tried to determine the rationality of his shame by examining his actions and omissions as a prisoner in the Lager and inquiring whether they might justify his shame. A positive answer to this question implies a description of what he did (or failed to do) as shameful. In other words, the question 'Is my shame rational?' seems to be transparent to the question 'Was what I did (or failed to do) shameful?', for whichever reasons may ground a certain answer to the last question would also ground a parallel answer to the first question, and vice versa (Evans 1982, Moran 2001, Dunn 2006). Moreover, when we look at Levi's experience from the viewpoint of the shamefulness of his actions or omissions, what becomes more significant is his emphasis on the need to suspend judgement on the side of a third party that might address the question 'Was what Levi did (or failed to do) shameful?' In fact, it is hard to imagine how a third party could ever feel entitled to answer this question positively and, yet, Levi himself did feel that he should answer it this way even though he was reluctant to imply that, as a result, someone else would be warranted to answer it the same way. To prevent this unwanted effect, we need to drop the Third-Party Assumption, so that Levi could approach his shame as revealing something of importance about his life so that, despite the lack of a reasonable degree of control, ${ }^{18}$ he could regard his faithfulness to it not only as proportionate but as rationally inescapable, as a case of practical necessity. It follows from the asymmetries so far highlighted that a third party cannot determine whether Levi's response is proportionate: this is only for Levi himself to acknowledge. The most a third party can do is to make room for 
such a manoeuvre, that is, to recognise that the conditions are given for them to suspend judgement. So, we can conclude that the asymmetries between the doer and a third party not only apply to the question about the rationality of Levi's shame but to those past actions and omissions that may lie behind it. What are, though, the implications of this asymmetry for the previous debate about the perspectival character of justification?

Consider, for this purpose, the question 'Is this action or decision justified?' We may then enquire as to how it must be answered. Suppose the action or decision at issue has produced some harm, as happens both in Levi's and Gauguin's cases. My point regarding Levi has been that the conditions under which this justificatory question can be answered highly depend on who raises it or, more exactly, on the questioner's situation with regard to the harm caused. In this respect, we may be inclined to think that harm has fundamentally two poles: the executioner and the victim. Still, the justificatory question is open to a further perspective, namely: that of a third-party. ${ }^{19}$ It would be naïve to regard this additional perspective as impartial, that is, as not perspectival at all; at least, this is an assumption that Levi's experience (and that of many other survivors) seems to challenge. In their view, there is no way in which a third party might be in a position to apprehend what the prisoners in Auschwitz were forced to go through, for their outlook is constrained by their own experience outside the Lager and, therefore, they look at it from a perspective alien to that of the prisoners and there is no way in which this external perspective could be vindicated as privileged or more authoritative. In fact, I have argued that, with regard to the question 'Were Levi's actions or omissions shameful and therefore unjustified?', a third party ought to suspend judgement..$^{20}$ It follows that the answer to the justificatory question is, at least on some occasions, relative to the questioner's situation with regard to the harm caused and, in this sense, situation perspectivism is trivially vindicated. In other words, a person's situation with regard to the three poles of harm determine what she might be entitled to say regarding the justificatory question and, consequently, this question can only be answered but relative to one or another situation.

Some might reply, however, that the variety of situations I have identified have little to do with the kind of variation that Williams and Wallace have in mind, for they are mainly concerned with a change of perspective that a certain person may undergo as a result of a certain decision or action of hers, whereas my previous remarks simply highlight the rather trivial fact that distinct persons may have disparate perspectives on a certain decision or action. It is easy to see, however, how the asymmetries between the doer and a third party that I have just presented have some significant implications for the kind of case Williams and Wallace are interested in. And, for this purpose, we may come back again to Levi's experience. He is 
placed, as we see, at some point in the arrow of time and looks back with shame. This is his view from here, but what was his view from there, that is, in the Lager when the relevant actions and omissions took place? What was his view at the time about those actions and omissions? He claims that he didn't think at the time that he was doing anything he might eventually feel ashamed of. He felt constrained by the circumstances; he struggled to survive in circumstances that left very little room for reflection and where the standard moral codes made little sense (Levi 1986: 61). So, there is a mismatch between Levi's view from here and his view from there as to whether his actions and decisions in the Lager were shameful and, therefore, unjustified. And, in this respect, a similarity with Gauguin's and the young mother's cases seems to have been established.

Still, some might insist that this was Levi's actual experience, perhaps shared by many other prisoners, and still there seems to be room for the normative question: was he justified in not feeling ashamed at the time? Wasn't after all his behaviour shameful and, in this respect, unjustified at the time? These questions presuppose that there is a view from which they can be meaningfully raised, but who could embody that view? It could not be Levi's view at the time as we have seen because his deliberative capacities were severely diminished by the circumstances he faced; it can't be Levi's view as a survivor either because his point of view has changed --it is no longer the point of view from there. So, it seems that it should be the view of a third party. In fact, a non-perspectival approach to justification must assume that the question about whether a certain action or decision is justified must be settled from the viewpoint of a thirdparty. The amount of reasons that this third party examines may, nevertheless, be confined to the reasons available to the doer or the decision maker at the time, or else be only constrained by the reasons available at the time to a privileged observer hypothetically placed there. In the first case, we could hardly conclude that Levi's actions or omissions were unjustified because part of his predicament lies in the fact that his deliberative capacities were severely diminished by the situation he faced and, therefore, we must allow for a mismatch between the view from there and the view from here in ways that we could hardly claim that the view from there should prevail, unlike what Wallace's non-perspectival approach vindicates. Should we opt for the second horn and go for the viewpoint of a privileged observer, we will be confronted with the fact that the idea of a privileged observer may not make any sense in this context. This is, at least, what follows from the claim that a third party, no matter how enlightened, must suspend judgement with regard to the question 'Was what Levi did (or failed to do) relevantly shameful?' In other words, the view from there construed in terms of a privileged observer is not a view that anyone could intelligibly occupy, once we drop the Third-Party Assumption in 
order to make sense of Levi's experience. So much for situation perspectivism, what about audience perspectivism?

The asymmetries between the three poles of harm allow us to understand the specific sense in which the drowned, and in general the wronged person, is the bearer of a claim and the specific ways in which she must deliberate. And this has, in my view, some implications for audience perspectivism. Let us return, for this purpose, to Gauguin's case. His wife and children were wronged by his decision and they are, as a result, the bearers of a claim. This condition implies that they are entitled to keep or withdraw their claim, even though such a decision must not be a matter of whim but the product of a specific kind of deliberation. This deliberation must be first-personal in such a way that what a third-party can legitimately say (including Gauguin and the mother themselves) falls short of determining what counts as a proper answer to the question 'Shall I keep or withdraw my claim?' when raised by the wronged person. If my line of reasoning is correct, the kind of deliberation that this question requires has to do with the victim's ability to discern what the situation may demand from her or, in other words, what is practically necessary for her to do. Only in these circumstances could we recognise her decision to keep or withdraw her claim as properly grounded. It follows that, contrary to what Wallace claims, a perspectival approach to justification helps us to understand the sense in which the wronged person is the bearer of a claim and, therefore, that some constraints are imposed on what a third party is entitled to say in cases of harm. How does this apply to Gauguin's deliberation? Could his decision emerge as justified in his own eyes despite what a third party or the wronged person might say?

I agree with Wallace that the mere fact that Gauguin is unable to regret his decision does not imply that it was justified. My point is, to begin with, that the actual dynamics of our attachments implies some asymmetries between the three poles of harm, so that the view from there may not always be regarded as privileged. But, once this is granted, we are deprived of a principled reason to examine Gauguin's decision from his perspective at the time and thus we must allow for circumstances where the view from here may prevail. So, we need some specific reason to exclude that Gauguin could retrospectively regard his decision as justified. This reason can no longer be that, in such a case, we could not recognise her wife as the bearer of a claim, since we have seen that this condition is better served by situation perspectivism than by a non-perspectival approach to justification, for my analysis implies that the wife's condition as the bearer of a claim can't be challenged by anything that Gauguin or a third party could say, not even the fact that they might in retrospect regard Gauguin's decision as justified. But this is exactly what audience perspectivism amounts to, namely: that the fact that Gauguin may 
legitimately regard his decision as justified does not call into question her wife's condition as the bearer of a claim.

Some might object, however, that there is a tension between claiming that Gauguin's decision was justified and acknowledging that his wife is the bearer of a claim, so that both views could not be coherently endorsed, for it is constitutive of being the bearer of a claim that she is entitled to accuse the executioner of having done something wrong, that is, something that cannot possibly be justified. But if Gauguin's wife is entitled to challenge his decision as unjustified, how could he still defend it is as justified? My suggestion is, however, that this perplexity presupposes that reason perspectivism is wrong, for the most Gauguin's wife could say is that her husband's decision was unjustified from the viewpoint of morality; she may even be convinced that this is the right perspective to take on this particular situation and she could provide some further moral reasons to back this second claim. Gauguin could reply, however, that he can't look at the situation but from a different perspective, namely, a perspective that is sensitive to moral reasons but also to non-moral ones; from this alternative perspective, the weight of his wife's claim will part of the cost Gauguin has to endure, but it will depend on the relative weight of the non-moral reasons under consideration as to whether he may entitled to embrace his decision as justified. ${ }^{21}$ In other words, Gauguin could coherently maintain that his decision is justified from his point of view, namely: a perspective that attaches a certain weight to moral reasons but denies their primacy; and still we could coherently acknowledge that from a moral perspective his wife is the bearer of a claim and his decision is unjustified. ${ }^{22}$ So, it sounds as if this line of objection constitutes a challenge to audience perspectivism only if we assume that moral reasons must always prevail but, in such a case, Wallace cannot embrace it, since he wants to keep reason perspectivism as a live option and, therefore, his challenge to audience perspectivism should hold regardless of one's views about reason perspectivism.

What about the young mother's case? In this case no one has actually been wronged, since as the story goes the daughter has actually been raised in a fairly good environment. And the intuitions I have exploited to highlight the deliberative asymmetries between the first- and the third-person perspectives have to do with cases, like Levi's and Gauguin's, where someone has actually been wronged. Alternative arguments could certainly be developed to defend this asymmetry even in cases where no harm has been produced; in my view, some such arguments could derive from a certain understanding of how conflicts of values must be dealt with, but we can safely leave such arguments aside, for all that is needed to challenge Wallace's nonperspectival approach to justification is the existence of a number of relevant cases where audience perspectivism is required to make sense of the actual dynamics of our attachments. Of 
course, some may feel tempted to dismiss Levi's experience as too extreme and exceptional to qualify as relevant and, therefore, to vindicate that our concept of justification should be explored on the basis of more familiar experiences and situations. I would not deny that Levi's experience is extreme. It is a bit harder for me to confirm that it is so exceptional in view of the massacres and genocides the past century have produced and those that are being produced right now (Glover 2001). Moreover, I am convinced that extreme cases of harm serve to highlight some aspects that tend to be occluded and denied in what may be regarded as more standard experiences of harm, like bullying, domestic violence or sexual abuse. But this is a point that goes beyond the scope of this paper (Corbí 2012: 2-3, 7).

Finally, some could certainly reply that, even though our notion of rationality does allow for the sort of asymmetries I have pointed out, there is room for a notion of justification that is immune to such asymmetries. In fact, this may be regarded as Wallace's main point, namely, to present justification as a normative dimension that, unlike others, is immune to all sorts of perspectivism. My concern with this alternative notion would not so much be that it might turn out to be unintelligible, but the fact that it could hardly play a significant role in our lives, for, if my line of reasoning is correct, any notion of justification that is sensitive to the actual dynamics of our attachments will be vulnerable to situation and audience perspectivism. More specifically, I have argued that only a perspectival notion of justification can account for the sense in which the wronged person is the bearer of a claim and, by these means, I call into question what I regard as Wallace's main argument for a non-perspectival view about justification, namely: that perspectival justification must be denied in order to make sense of the fact that the wronged person is the bearer of a claim.

\section{Conclusion}

Wallace defends a non-perspectival approach to justification. For this purpose, he challenges Williams' argument for retrospective justification on the basis that Gauguin's success as a painter prevents him from regretting his decision to leave his family in the lurch. I have suggested that Williams' analysis of this case involves three perspectival aspects that can be expressed as situation, audience and reason perspectivism. Wallace wants his argument to be neutral with regard to the primacy of moral reasons and, therefore, suspends judgment regarding reason perspectivism, but he objects to situation and audience perspectivism. In light of the actual dynamics of Levi's experience, I have argued that harm has three poles and also that, at least in such cases, justification is relative both to the questioner's situation and to the 
audience to which her answer may be addressed. As a result, Wallace he seems to be caught in a dilemma: either he renounces the normative role that he explicitly grants to the actual dynamics of our attachments in his defence of the rationale of regret or he allows for situation and audience perspectivism. In other words, he cannot coherently preserve two fundamental claims in his book, namely: a non-perspectival approach to justification and a vindication of the rational regret in terms of the normative authority of the actual dynamics of our attachments. ${ }^{23}$

\section{References}

Corbí, J. E. (2012), Self-Knowledge, Morality and Human Suffering. New York: Routledge.

---(2014), 'Self-Knowledge, Authenticity and Obedience', Bollettino Filosofico 29, 48-72.

Dunn, R. (2006), Values and the Reflective Point of View: On Expressivism, Self-Knowledge and Agency. Aldershot, UK: Ashgate.

Evans, G. (1982), The Varieties of Reference. Oxford: Oxford University Press.

Finkelstein, D. (2003), Expression and the Inner. Cambridge, MA: Harvard University Press.

Glover, J. (2001), Humanity. A Moral History of the Twentieth Century. New Haven: Yale

University Press.

Goodman, N. (1983), Fact, Fiction and Forecast. Cambridge: Harvard University Press.

Levi, P. (1986), The Drowned and the Saved. London: Abacus.

Moran, R. (2001), Authority and Estrangement: An Essay on Self-Knowledge. Princeton: Princeton

University Press.

Rawls, J. (1999), The Theory of Justice. Oxford: Oxford University Press.

---(2001), Justice as Fairness. Cambridge, MA: Harvard University Press.

Strawson, P. F. (2008), Freedom and Resentment and Other Essays. London: Routledge.

Stroud, B. (2000), The Quest for Reality: Subjectivism and the Metaphysics of Colour. Oxford:

Oxford University Press.

---(2011), Engagement and Metaphysical Dissatisfaction. Oxford: Oxford University Press.

Wallace, J. (1996), Responsibility and the Moral Sentiments. Cambridge, Mass: Harvard

University Press.

---(2006), Normativity and the Will. Oxford: Oxford University Press.

---(2013), The View from Here: On Affirmation, Attachment and the Limits of Regret. Oxford:

Oxford University Press.

Weil, S. (1963), Gravity and Grace. London: Routledge. 
Williams, B. (1981), 'Moral Luck, in idem, Moral Luck. Cambridge: Cambridge University Press.

---(2002), Truth and Truthfulness. Princeton and Oxford: Princeton University. Press.

\author{
Josep E. Corbí \\ University of Valencia \\ Av. Blasco Ibáñez 30 \\ 46010-Valencia (Spain) \\ Josep.Corbi ç uv.es
}

${ }^{1}$ To describe Wallace's conception of Gauguin's predicament in a more precise manner, we should mention a number of distinctions that Wallace (2013) introduces, namely: all-in regret vs. regrets, affirmation vs. all-in regret, and conditional vs. unconditional affirmation. But we can dispense with them for the purposes of this paper.

2 'There can be no real question for us of ceasing altogether to care about things, and the emotions to which we are susceptible in virtue of this valuing stance are in that way beyond justification.' (Wallace 2013: 32)

${ }^{3}$ '... Attachment is valuable in itself, at least when it latches onto appropriate objects of evaluative concern.' (Wallace 2013: p. 31, see 29-30)

${ }^{4}$ Wallace (1996) explicitly defends the existence of a constitutive connection between responsibility and our reactive attitudes: 'For my part, what I find promising in Strawson's position are not so much the official answers he provides to the question of the compatibility of responsibility with determinism, as the suggestions he makes about the connection between responsibility and the moral sentiments... the interpretation of responsibility, as distinctively linked with our moral sentiments, provides the framework within which a more satisfactory response may be devised.' (Wallace 1996: 10). See Wallace (2006: 1) for a similar point. ${ }^{5}$ A similar apparent inconsistency is to be found in Wallace's vindication of what he refers to as 'the realism condition', that is, the idea that an unconditional affirmation of $\mathrm{X}$ commits the 
agent to affirm all the constitutive and causally necessary conditions for X. Sometimes this condition is presented as a mere rationality constraint whereas in some other cases, like in the following quote, it is apparently concerned with the possibilities that are psychologically available to us: 'At any rate, I cannot regret on balance this latter fact unless I am (again) ignorant or confused about the necessary conditions for our going on the expedition that I affirm. This is the sense in which on-balance affirmation commits one to affirming as well the necessary causal conditions of the thing that one affirms. There is no psychological space for affirming the object while regretting on balance its necessary conditions, so long as one is clear that the conditions really are necessary for the thing that one affirms.' (Wallace 2013: 73) My suggestion again is to make these two remarks consistent by assuming that at least some normative facts are to be individuated relative to some psychological facts, and vice versa. ${ }^{6}$ See Wallace (2006: 71-82) for a taxonomy of realist views about morality and the sort of moral realism he endorses:

It sometimes seems as if there are as many versions of moral realism as there are moral realists. But one thing that most realist positions have in common is the following. They can be understood as attempts to give expression to the idea that discourse in a certain domain is answerable to a reality that is in some sense prior to and independent of us... The difficulty is that talk about the concept or agent independence of entities or facts is rather dark, and admits of a variety of incompatible interpretations. (Wallace 2006: 72)

'Independent of us' in this quotation is to be construed as just independent of any individual human will: 'The alternative approach that I myself favor is NMR [Normative Moral Realism]. This approach holds that there are normative truths that are prior to and independent of the individual human will.' (Wallace 2006: 80)) Hence, the version of NMR that Wallace defends does not exclude that moral facts could depend on human moral sentiments in general, but only 
that they could be relative to the will of a particular individual.

${ }^{7}$ Some reasons are not grounded on any specific attachments, like those that derive from morality (Wallace 2013: 10).

8 'It may be said that this merely represents our gratitude that morality does not always prevail -

- that moral values have been treated as one value among others, not as unquestionably

supreme. I think that that misdescribes our relation to this Gauguin, at least, but it is important also to bear in mind the grounds, the scope and the significance of that gratitude, which I mentioned earlier, for the limitations of morality. If the moral were really supreme, it would have to be ubiquitous.' (Williams 1981: 37-8)

9 'It is a live question whether moral claims or obligations always trump the considerations with which they might conflict, and, if not, whether the aesthetic issues that are implicated in the Gauguin case are of the kind that might suffice to defeat them.' (Wallace 2013; 165). See Wallace (2006: 123-143) for a discussion of this issue. There, Wallace distinguishes between the standpoint of morality and the eudaimonistic standpoint, but denies that there could be a wider perspective from which they could be unified. Still, he argues that the demands of morality have a bearing on what counts as a good life and, therefore, within eudaimonistic deliberation. This does not imply, however, the optimality thesis, that is, 'that someone has most reason to comply with moral demands' (Wallace 2006: 130). In fact, he concludes that his line of argument falls short of proving that a necessary condition to have a good life is to comply with morality (Wallace 2006: 137).

${ }^{10}$ My point at this stage is not so much that we cannot properly account for Gauguin's case without assuming reason perspectivism, but only that it is hard to make sense of Williams' account of this case without regarding him as committed to this sort of perspectivism.

${ }^{11}$ Wallace often appeals to the intuition that justification has to do with what the agent had reason to do at the time of the decision, but he does not develop any specific argument in 
favour of this claim that is so fundamental to his approach. I assume he takes it as the default assumption about justification and, therefore, he feels entitled to displace the burden of proof on his opponent.

${ }^{12}$ Some could reply that, in cases of moral dilemmas, the wronged person is not the bearer of a claim, precisely because the agent was justified in embracing one of the horns of the dilemma. But the same line of reasoning could apply to Gauguin's decision if we renounce the primacy of moral reasons. Hence, it seems that this asymmetry between moral dilemmas and Gauguin's case also presupposes taking sides on reason perspectivism in contrast with the neutral attitude that Wallace wants to preserve.

${ }^{13}$ My line of reasoning points to a notion of first-person deliberation that is stronger than Wallace's notion of agent-relative reason, for, as I argued in section 1, the latter seems to reduce to the fact that some reasons are relative to the agent's situation and, therefore, they apply to any agent in the same situation and, in this sense, they can be determined from a thirdperson perspective.

${ }^{14}$ Insofar as practical necessity has to do with an imposition that comes from outside, it can also be regarded as emerging from deep inside, that is, from an aspect of the agent's psychology that is deeper than an act of will or an idiosyncratic psychological disposition. How this connection between the deep inside and the normative outside is to be articulated, is an issue I cannot properly address in the present paper, but I have elaborate in some detail in Corbí (2012: ch. 46; 2014) along the lines suggested by Stroud (2000, 2011). See also Finkelstein (2003: ch. 4-5). ${ }^{15}$ In a similar way, Williams claims: 'The recognition of practical necessity must involve an understanding at once of one's own moral powers and incapacities, and of what the world permits, and the recognition of a limit which is neither simply external to the self, nor yet a product of the will, is what can lend a special authority or dignity to such decisions -something that can be heard in Luther's famous saying, for instance, but also, from a world far removed 
from what Luther, Kant, or we, might call 'duty', in the words of Ajax before his suicide: 'now I am going where my way must go' (Williams 1981: 130-1; see Weil 1963: 38-44).

${ }^{16}$ In Corbí (2012: ch. 1), I develop a similar line of argument to challenge the relevance of Rawls' original position to detemine the principles of justice.

${ }^{17}$ Assumptions (a) and (b) are closely interlocked. Assumption (b) can reasonable be challenged only once assumption (a) has been dropped, for the deliberative asymmetry between the firstand the third-person perspectives only applies to those cases where the agent is held responsible despite the fact that she did not have enough margin of manoeuvre.

${ }^{18}$ The need to renounce the Control Assumption is suggested by Levi himself when he emphasises that 'no man is an island' and that other people's guilt is one's own too. (Levi 1986:

${ }^{19}$ I could hardly overemphasise the significance of a third party in the experience of harm, but this is a fundamental issue I have already explored on some other occasion.

${ }^{20}$ Levi regards himself as a victim and an executioner, but rejects that a third-party could be entitled to approach him for the latter perspective. Still, he envisages himself this way in relation to the drowned who are the true victims and it is only with regard to them that he feels the need to confess that he did something shameful. This doesn't imply he should be ready to accept an accusation on the side of the drowned, since it seems that, like Levi himself with regard to the members of the Sondernkommandos, they ought to suspend judgment.

${ }^{21}$ In cases of serious harm it is hard to see how non-moral reasons could outbalance the moral cost of certain decisions or actions. In such cases, someone could only justify her decision from a viewpoint that is insensitive to moral reasons which, ex hypothesis, is not Gauguin's case. ${ }^{22}$ A most significant question is how a person relates to her point of view; whether it is a matter of choice to shift from one to another point of view or whether it has to do with the idea of practical necessity. Needless to say, I am rather inclined to favour this second option. In this 
sense, we could say that both Gauguin and his wife are somewhat anchored to their respective point of view and the conditions under which they could shift from one to another depend on a certain transformation that cannot be induced by a decision or by an act of will.

${ }^{23}$ I am indebted to my colleagues in the Phronesis Weekly Seminar for their kind but strong criticism of an early draft of this paper. Their suggestions and challenges have certainly inspired this final version. I have also benefited from the questions and remarks of the participants in 9 th Nomos Meeting: The View From Here (Valencia, June 2-3, 2014) and in The Scope and Limits of Responsibility (Valencia, November 19-20, 2015). I must thank Ignacio Ávila, Christopher Bennett, Laura García Portela, Manuel García-Carpintero, , Carmen Santander and Angela Uribe for a detailed and enlightening discussion of various aspects of this paper. And I am finally pleased to acknowledge that research for this paper has been funded by Spanish Ministry of Economy and Competitivity (CSD2009-00056, FFI2013-47948-P, FFI2014-55256-REDT). 